\title{
Association of Health Insurance and Documentation with Stigma and Social Support Among Myanmar Migrants with Tuberculosis Before and During Thailand's Policy on Border Closure Due to COVID-19: a Cross-Sectional Study
}

\author{
Myo Minn Oo ${ }^{1} \cdot$ Tippawan Liabsuetrakul $^{1}$ (D) Naris Boonathapat ${ }^{2} \cdot$ Htet Ko Ko Aung $^{3} \cdot$ Petchawan Pungrassami $^{4}$
}

Received: 26 May 2021 / Revised: 31 October 2021 / Accepted: 2 November 2021 / Published online: 22 November 2021

(c) W. Montague Cobb-NMA Health Institute 2021

\begin{abstract}
Objective The objective of this study was to assess the effect of health insurance and documentation status on tuberculosis (TB)-related stigma and social support before and during Thailand's policy on border closure.

Methods A cross-sectional study was conducted in two TB clinics in Mae Sot district, a border area of Thailand. Myanmar migrants with new TB were interviewed before (between September 2019 and March 2020) and during Thailand's policy (between April 2020 and January 2021). We used multiple linear regression models to assess the association of health insurance and documentation status with stigma and social support before and during the policy on border closure.

Results Of 229 migrants diagnosed new TB recruited, 117 and 112 were interviewed before and during Thailand's policy on border closure. The relationship of stigma with health insurance and documentation status was modified by the policy. Migrants with health insurance reported significantly lower stigma during the policy compared to those without health insurance, whereas documented migrants had lower stigma before the policy compared to undocumented migrants. No significant association of health insurance and documentation status with social support was observed. Ethnicity, perceived TB severity and education level were also independently associated with TB-related stigma.

Conclusion The relationships between health insurance, documentation status and TB-related stigma were modified by Thailand's policy on border closure among Myanmar migrants with TB in a border area of Myanmar and Thailand. Promotion of health insurance and well-planned documentation for migrants should be more discussed and strengthened among stakeholders and policymakers.
\end{abstract}

Keywords Thailand's policy on border closure $\cdot$ Myanmar migrants $\cdot$ Tuberculosis $\cdot$ TB-related stigma $\cdot$ Social support

\section{Introduction}

Tippawan Liabsuetrakul

ltippawa@yahoo.com

1 Epidemiology Unit, Faculty of Medicine, Prince of Songkla University, Hat Yai, Songkhla, Thailand

2 Mae Sot General Hospital, Mae Sot, Tak, Thailand

3 Shoklo Malaria Research Unit, Mahidol-Oxford Tropical Medicine Research Unit, Faculty of Tropical Medicine, Mahidol University, Bangkok, Thailand

4 Bureau of Tuberculosis, Ministry of Public Health, Nonthaburi, Thailand
Globally tuberculosis (TB) remains a major public health concern. In 2019, approximately 10 million people fell ill with TB with about 1.2 million deaths. Thailand and Myanmar are in the top 30 high TB-burden countries [1]. The Thailand-Myanmar border that hosts a substantial number of Myanmar migrants has long been regarded as a challenging zone for local and national TB control [2, 3 ], and migrants are included in high-risk populations for TB [4]. Stigma, a social determinant of health, is characterized by perception, anticipation, and/or experiences of adverse social judgement of TB patients [5, 6]. The predisposing psychological distress and common mental disorders may be worsened by their migratory nature [7], 
but social support may play a role in mitigating the effect [8].

Thailand is one of a few countries in Southeast Asia that offer comprehensive health insurance packages to migrant populations [9]. While health insurance is a safeguard that can help migrants have timely access to essential quality healthcare, the literatures suggested that a substantial proportion of migrants do not have health insurance $[9,10]$. In addition, undocumented migrants most often do not have health insurance, nor access to proper healthcare. Their migratory status, in addition to health insurance and documentation status, are likely to expose them to more stigma, drastic changes in social support, feelings of isolation, limited health-seeking behavior, and drug adherence $[6,11]$. Hence, TB stigma among migrants is an important problem, presenting a double burden to Thailand [12]. Studies among Myanmar migrants on Thailand-Myanmar border highlighted challenges of health insurance and documentation status in migrant healthcare and suggested the need for further research on stigma and social support [13, 14]. Furthermore, stigma complicates the care, prevention, and control of infections including TB and coronavirus disease 2019 (COVID-19) [15]. The COVID-19 pandemic, on the other hand, can widen the gap of inequality in TB care [16] and worsen stigma and social discrimination [15].

With the declaration of COVID-19 pandemic in March 2020 [17], Thailand's policy on border closure including Thailand-Myanmar border has been announced in early April 2020. How health insurance and documentation status affect stigma and social support experienced by migrants before and during Thailand's policy on border closure is not well understood. Wearing masks, frequent hand washing, and physical distancing have become the most important health behavior changes in order to prevent and control COVID-19 pandemic [18]. Although these measures may make TB patients feel invisible and less stigmatized, infectious diseases including TB and COVID-19 can be manifested with health-related stigma due to their similarity in symptoms [15], as well as due to pandemic related socio-economic impacts such as limited mobility, job insecurity, and emerging social problems such as domestic violence [19]. The dynamic between health insurance, legal documentation status with stigma, and social support among migrants related to TB in this border area is limited. Until now, little has been known about the effects of this recent introduction of policy on border closure to this dynamic. Hence, in this study, we assessed the effect of health insurance and documentation status on TB-related stigma and social support before and during Thailand's policy on border closure due to COVID-19.

\section{Methods}

\section{Study Design}

A cross-sectional survey was conducted in two TB clinics, one at Mae Sot district hospital and another at Shoklo Malaria Research Unit (SMRU)'s TB clinic, in Mae Sot district, Tak province, a border area between Thailand and Myanmar.

\section{Setting}

Thailand and Myanmar are neighboring countries in the Southeast Asia region with a shared border of 2,418 kilometers (km). Mae Sot, $492 \mathrm{~km}$ away from Bangkok, the capital of Thailand, is the most populous border area in the western part of Thailand, as shown in Fig. 1. Mae Sot district hospital and Shoklo Malaria Research Unit (SMRU) run two major TB clinics for Myanmar migrants that collaborate with Thai Health Authority and other non-profit organizations in the region to provide TB care and treatments. They provide care for more than 200 new TB cases annually.

Following Thailand's policy on border closure due to COVID-19 in April 2020, Mae Sot also imposed strict COVID-19 measures including closure of major public centers as well as closure of Thailand-Myanmar border point [19]. An assessment in May 2020 indicated that almost 75\% experienced partial loss of income and $25 \%$ were unable to meet basic needs [20]. They had very limited options to return to Myanmar as the border was also closed and had little access to government aid in Thailand, especially if they were undocumented. Similar to other provinces in Thailand, hand washing, wearing masks, and physical distancing had become a new norm in Mae Sot, and the majority of the migrants were well-informed about COVID-19 symptoms, hygiene, and sanitation. However, migrants, especially those undocumented, usually live in cheap cramped dormitories and housing facilities with poor sanitary conditions. Border closure also restricts the mobility of migrants, having fewer options to find new jobs. Police arrest due to visa overstay or illicit attempts to return to Thailand during border closure is also a common issue [20].

\section{Study Sample}

All Myanmar migrants aged 18 years or above diagnosed new TB who had received less than 2 months of anti-TB treatment at the study clinics before (between 1st September 2019 and 31st March 2020) and during Thailand's policy on border closure (between 1st April 2020 and 15th January 2021) were included in the study. Multi-drug resistant 
Fig. 1 Map showing the border area between Myanmar and Thailand. Available from: https://www.google.com/maps/ dir/Bangkok/Mae+Sot,+Mae+ Sot+District

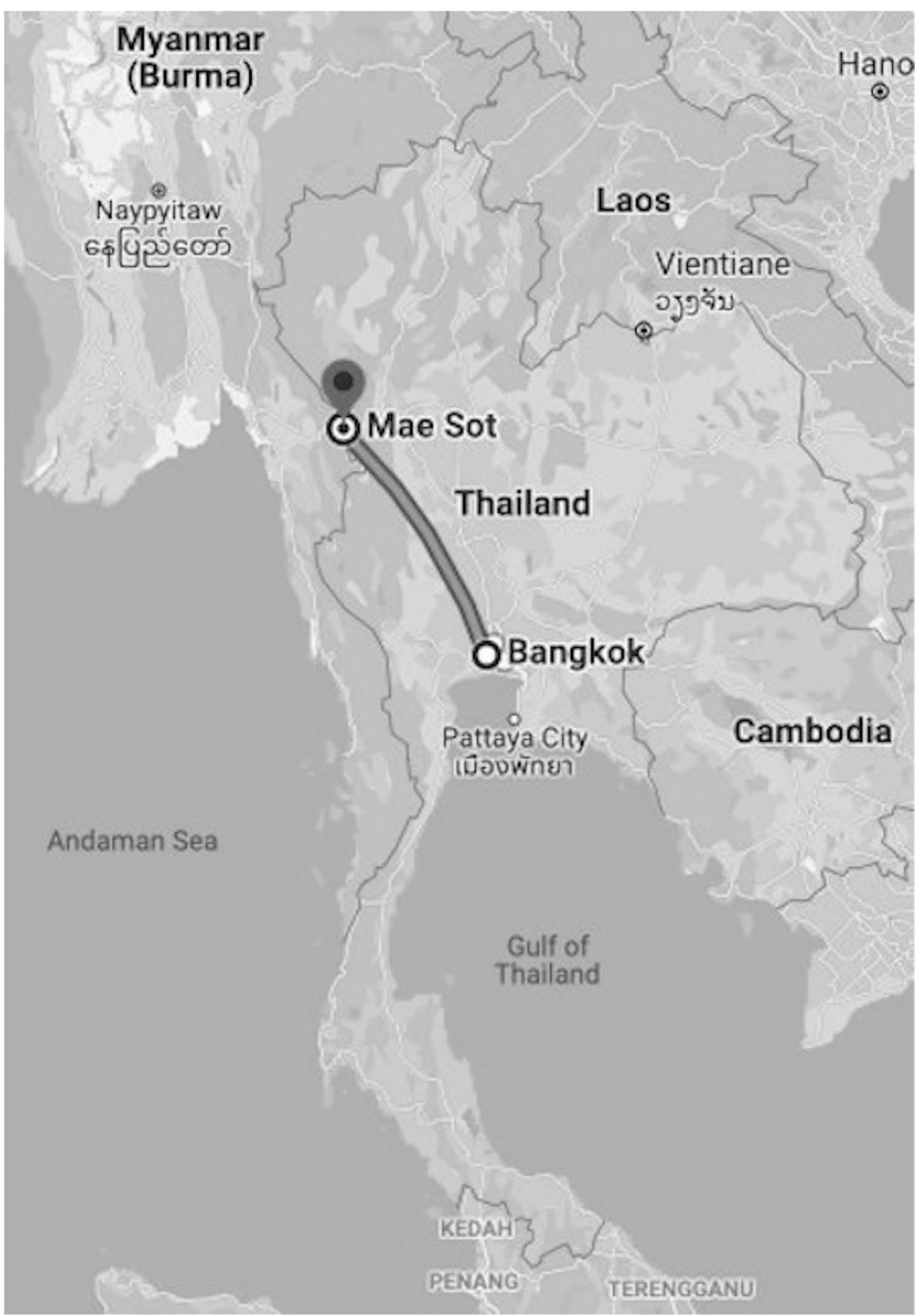

patients, prisoners, or critically ill cases were excluded from the study. To our knowledge, few previous studies assessed TB-related stigma or social support in the context of migrants $[6,21]$, whereas no previous studies considered stigma and social support scores by health insurance or documentation status. Hence, we assumed $20 \%$ difference in stigma scores among migrants with and without health insurance status before and during the policy on border closure in Thailand. Hence, we estimated mean scores of 30 and 25 , and standard deviation of 8 , respectively, and the margin of error of $1,95 \%$ confidence interval, and a power of $80 \%$. The final sample size was 205 Myanmar migrants required after adjusting for the design effect of 1.5.

\section{Key Variables and Definitions}

A structured questionnaire to record the characteristics of the participants including TB knowledge, perceptions of TB severity, patient satisfaction with health services, TB-related stigma, and Index of Sojourner Social Support (ISSS) was 
used. Characteristics consisting of age; sex; ethnicity (Burmese, Karen, or others); education levels (primary school and below or above primary school); having a job at TB diagnosis; residing in Mae Sot city; type of household (living alone, with family or with other people); health insurance status at TB diagnosis; documentation status, either legal resident or work permits, indicating the legal documents to stay and/or work in Thailand; and income level in Baht were obtained from patient interviews. The ability to understand Thai local language was also noted.

The World Health Organization (WHO) TB knowledge, attitude, and practices survey was adapted to measure participants' TB knowledge level based on five questions regarding symptoms of TB (cough for $>2$ weeks, cough with sputum, hemoptysis, chest pain, weight loss, fever, and night sweat), route of transmission, curability, prevention, and treatment of TB [22]. For each question or item correctly identified, a score of 1 was given, and 0 otherwise. The minimum score was 0 , and the maximum possible score was 16 . Six items including the effect of TB on their lungs, disturbing normal daily activities, TB being the most terrible event, disturbing family relations, concerns for working, and risk of transmission to other people were also used to explore the patients' perceptions of TB severity. The scale was measured using a 5-point Likert scale (1, strongly agree; 2 , agree; 3 , uncertain; 4 , disagree; and 5 , strongly disagree). Scores were calculated with a minimum score of 6 and maximum score of 30 . Total scores were then computed for analyses.

We also assessed satisfaction with current health services at the clinic using Patient Satisfaction Question Short-Form 18 (PSQ-18). PSQ-18 is a valid and widely used 18-item scale which can be used in different settings [23]. Higher scores indicated greater satisfaction with current health services.

For TB-related stigma, we used a validated scale developed in Thailand by Van Rie et al. [24], which measured the patient perspectives of TB using 12 items and the community perspectives of TB using 11 items. Each item was rated by 5-point Likert responses from 0 to 4 , with 0 representing "strongly disagree" and 4 representing "strongly agree" with the stigma. Since the two perspectives of TB had different numbers of items, the total scores of each perspective were standardized using the formula $S S_{50}=\left(S S_{\text {raw }} \times 50\right) /(n \times 4)$, where $S S_{50}$ represents standardized summary score, $S S_{\text {raw }}$ raw summary score, and $n$ the number of items in each scale. Therefore, the standardized stigma scores would lie between 0 and 50, with higher scores meaning higher level of stigma. The mean and standard deviation of the $S S_{50}$ in the study population were then estimated [24].

We also used the Index of Sojourner Social Support (ISSS), which is a validated scale to assess social support in the context of immigration $[21,25]$. The ISSS measured socio-emotional support ( 9 items) and instrumental support
(9 items). Responses were on a 5-point Likert scale ( 0 , "No one would do this"; 1, "Someone would do this"; 2 , "A few would do this"; 3 , "Several would do this"; 4, "Many would do this." The scores would lie between 0 and 72, and higher score indicated higher social support. The final scores for each sub-scale were calculated by summing all the responses under each scale.

\section{Data Collection}

The questionnaire was pretested with other Myanmar migrants with TB receiving treatment at the clinics before the implementation to reassure the migrant's understanding on the items in the questionnaire and improve the validity of the data. In order to minimize interviewer bias, two research assistants, who speak both Burmese and Karen and had previous experience working in this healthcare setting, but not in participating clinics, were recruited and trained prior to the study.

\section{Statistical Analysis}

Data were entered into EpiData Manager and EntryClient Software version 4.6.0.2 and analyzed using $R$ version 4.0.3 (the R Foundation for Statistical Computing, Vienna, Austria, 2020). Scores for TB knowledge, perceptions of TB severity, and patient satisfaction were dichotomized into low and high levels using their mean values. We compared scores of TB-related stigma and social support scales across variables using $t$ test and one-way analysis of variance. The policy variable was created by dichotomizing the migrants with TB into two groups: the group before the Thailand policy on border closure (those interviewed between $1 \mathrm{st}$ September 2019 and 31st March 2020) and the group during the policy (those interviewed between 1st April 2020 and 15th January 2021). Mean score differences in stigma and social support scales disaggregated by health insurance and documentation status before and during the policy on border closure were compared using independent $t$ tests.

The factors associated with TB-related stigma and ISSS scores were analyzed by multiple linear regression models, using ordinary least squares. The final models were adjusted by covariates including ethnicity, education level, occupation, local language, type of household, income level, and perception of severity of TB. Health insurance and documentation status were the main exposures of interest in this study and were adjusted in all models. Interaction between the policy on border closure due to COVID-19, health insurance, and documentation status were used to assess the effect of the COVID-19 policy on the association between health insurance/documentation and stigma/social support. Adjusted beta ( $\beta$ )-coefficients were presented with their $95 \%$ 
confidence intervals $(95 \% \mathrm{CI})$, and significance level was set to 0.05 .

\section{Results}

A total of 229 Myanmar migrants with TB were recruited at the two clinics during the study period. Table 1 describes TB-related stigma by different characteristics of participants. The means (standard deviations) of stigma scores of both patient and community perspectives were $27.0(8.9)$ and 30.4 (9.2), respectively. Migrants with TB who had education above primary school or Karen migrants were less likely to have stigma of patient perspectives or community perspectives, respectively. Those with high levels of perceived TB severity were more likely to have stigma of both patient and community perspectives, respectively. Migrants with health insurance had significantly lower stigma of patient and community perspectives. Only stigma of patient perspective was significantly lower in documented migrants. TB-related stigma scores, across the study's variables based on the Thailand policy on border closure, were also explored in Supplementary Table S1.

Table 2 presents the effects of health insurance, documentation status, the policy on border closure due to COVID-19 adjusted with other potential confounders, and the interaction between health insurance and documentation status. The interaction between the policy and health insurance was significantly negative on both subscales of stigma ( $p=0.013$ and $p=0.034$ ). This indicated that compared to those without health insurance, migrants with health insurance reported much lower stigma scores of both patient and community perspectives during the policy than before the policy. The interaction between the policy and documentation status was significantly positive on both subscales of stigma ( $p=0.008$ and $p=0.019)$. This indicated the effect of documentation status on both subscales of stigma was modified by the policy. Karen ethnicity, living with family, and low level of perceived TB severity were associated with lower stigma of patient and community perspectives, while having an education above primary school and living with other people were associated with lower stigma of patient perspectives.

Due to the significance of two interaction terms, the stigma scores stratified by health insurance and documentation status before and during Thailand's policy on border closure are shown in Table 3. Only documented migrants had significantly lower stigma scores of both patient and community perspectives before the policy. Only migrants with health insurance had significantly lower stigma of both patient and community perspectives during the policy.

Table 4 shows social support by different characteristics of participants. The means (standard deviations) of socio-emotional and instrumental support were 13.7 (7.8) and 13.2 (8.1), respectively. Migrants who had education level above primary school and those who had health insurance were likely to have higher socio-emotional and instrumental social support. Migrants aged 31-40 years, those who had job at TB diagnosis, and those with high TB knowledge were significantly more likely to have instrumental social support. Social support scores, across the study's variables based on the policy consideration, were also explored in Supplementary Table S2. No significant associations of health insurance and documentation status with social support were observed in multivariate analysis (Table 5). Age group between 31 and 40 years $(p=0.042)$ and having education above primary school level $(p=0.018)$ were associated with higher socio-emotional support, while high level of TB knowledge was associated with higher instrumental support. Scores of socio-emotional and instrumental social supports before and during Thailand's policy on border closure due to COVID-19 are presented in Table 6.

\section{Discussion}

Thailand's policy on border closure due to COVID-19 was an effect modifier in the relationships of stigma with health insurance and documentation status. Lower TB-related stigma among migrants with health insurance only during the policy and among documented migrants before the policy was shown. Ethnicity, type of household, perceived TB severity, and education level were also independently associated with TB-related stigma. No effects of health insurance, documentation status, and the policy on social support were observed. High stigma and low social support were found in migrants with TB.

The effect of health insurance and documentation status on TB-related stigma among Myanmar migrants with TB was modified by Thailand's policy on border closure. To our knowledge, there were no previous studies assessing the impact of the policy on border closure due to COVID-19 on TB-related stigma. The explanation may be that the migrant population is hard to reach under these circumstances, and it was difficult to conduct the study during the policy. Our study found lower TB-related stigma among migrants with health insurance only during the policy and among documented migrants before the policy. This may be the new norm of wearing masks in public areas during COVID-19 pandemic [18] which was similar to the recommendation of public mask-wearing in TB patients to control TB transmission [26].

The TB migrants with health insurance had lower stigma of both patient and community perspectives compared with those without health insurance during the policy on border closure due to COVID-19 which could be related to the 
Table 1 Tuberculosis-related stigma scores in different characteristics of participants

\begin{tabular}{|c|c|c|c|c|c|}
\hline \multirow[t]{2}{*}{ Variable } & \multirow[t]{2}{*}{ Total $n(\%)$} & \multicolumn{2}{|c|}{ Patient perspectives } & \multicolumn{2}{|c|}{ Community perspectives } \\
\hline & & Mean $(S D)$ & $p$ value & Mean $(S D)$ & $p$ value \\
\hline Total & $229(100)$ & $27.0(8.9)$ & & $30.4(9.2)$ & \\
\hline Age categories (years) & & & 0.114 & & 0.077 \\
\hline $18-30$ & $70(30.6)$ & $25.1(8.0)$ & & $28.3(9.5)$ & \\
\hline $31-40$ & $67(29.3)$ & $28.0(8.8)$ & & $31.6(9.0)$ & \\
\hline $41-80$ & $92(40.2)$ & $27.6(9.4)$ & & $31.1(9.1)$ & \\
\hline Sex & & & 0.444 & & 0.863 \\
\hline Male & $142(62.0)$ & $26.4(8.5)$ & & $30.5(9.7)$ & \\
\hline Female & $87(38.0)$ & $27.3(9.1)$ & & $30.3(9.0)$ & \\
\hline Ethnicity & & & 0.114 & & 0.021 \\
\hline Burmese & $140(61.1)$ & $27.8(8.9)$ & & $31.5(9.3)$ & \\
\hline Karen & $52(22.7)$ & $24.8(8.2)$ & & $27.3(9.0)$ & \\
\hline Others & $37(16.2)$ & $26.9(9.4)$ & & $30.6(8.6)$ & \\
\hline Education level & & & 0.002 & & 0.097 \\
\hline Primary school and below & $130(56.8)$ & $28.5(8.9)$ & & $31.3(9.4)$ & \\
\hline Above primary school & $99(43.2)$ & $24.9(8.4)$ & & $29.2(8.9)$ & \\
\hline Had job at TB diagnosis & & & 0.733 & & 0.594 \\
\hline Yes & $189(82.5)$ & $26.5(10.2)$ & & $31.2(10.6)$ & \\
\hline No & $40(17.5)$ & $27.1(8.6)$ & & $30.2(8.9)$ & \\
\hline Residing in Mae Sot & & & 0.402 & & 0.529 \\
\hline No & $57(24.9)$ & $27.8(8.2)$ & & $31.0(8.2)$ & \\
\hline Yes & $172(75.1)$ & $26.7(9.1)$ & & $30.2(9.5)$ & \\
\hline Type of household & & & 0.040 & & 0.155 \\
\hline Living alone & $41(17.9)$ & $30.1(8.4)$ & & $32.9(7.6)$ & \\
\hline Living with family & $168(73.4)$ & $26.4(9.0)$ & & $29.9(9.5)$ & \\
\hline Living with other people & $20(8.7)$ & $25.2(7.8)$ & & $29.4(9.6)$ & \\
\hline Health insurance status & & & $<0.001$ & & 0.015 \\
\hline No & $156(68.1)$ & $28.5(8.6)$ & & $31.4(9.1)$ & \\
\hline Yes & $73(31.9)$ & $23.8(8.7)$ & & $28.2(9.1)$ & \\
\hline Documentation status & & & 0.012 & & 0.085 \\
\hline No & $104(45.4)$ & $28.6(8.3)$ & & $31.6(9.0)$ & \\
\hline Yes & $125(54.6)$ & $25.6(9.2)$ & & $29.4(9.3)$ & \\
\hline Thai language & & & 0.488 & & 0.555 \\
\hline No or a few words & $197(86.0)$ & $26.8(8.8)$ & & $30.6(9.1)$ & \\
\hline Fluent & $32(14.0)$ & $28.1(9.7)$ & & $29.4(9.9)$ & \\
\hline Income level (Baht) & & & 0.088 & & 0.179 \\
\hline$<5000$ & $90(39.3)$ & $28.6(8.6)$ & & $31.4(9.1)$ & \\
\hline$\geq 5000$ & $121(52.8)$ & $26.0(8.8)$ & & $29.4(9.1)$ & \\
\hline None & $18(7.9)$ & $25.8(10.1)$ & & $32.5(10.3)$ & \\
\hline TB Knowledge & & & 0.162 & & 0.174 \\
\hline High & $100(43.7)$ & $27.7(8.4)$ & & $31.1(8.6)$ & \\
\hline Low & $129(56.3)$ & $26.0(9.4)$ & & $29.4(9.9)$ & \\
\hline Perception of severity of TB & & & $<0.001$ & & 0.002 \\
\hline High & $97(42.4)$ & $29.0(8.4)$ & & $32.0(9.1)$ & \\
\hline Low & $132(57.6)$ & $24.2(8.8)$ & & $28.2(9.1)$ & \\
\hline Patient satisfaction with health services & & & 0.352 & & 0.912 \\
\hline High & $94(41.0)$ & $26.3(9.6)$ & & $30.2(9.7)$ & \\
\hline Low & $127(55.5)$ & $27.5(7.8)$ & & $30.5(8.5)$ & \\
\hline Bacteriologically confirmed TB & & & 0.761 & & 0.476 \\
\hline Yes & $118(51.5)$ & $26.8(8.7)$ & & $30.0(9.5)$ & \\
\hline No* & $111(48.5)$ & $27.1(9.1)$ & & $30.8(9.0)$ & \\
\hline
\end{tabular}

$S D$ standard deviation; $T B$ tuberculosis; *Included smear negative/clinician diagnosed TB/extrapulmonary TB 
Table 2 Final linear regression model of factors associated with tuberculosis-related stigma scores

\begin{tabular}{|c|c|c|c|c|}
\hline \multirow[t]{2}{*}{ Variable } & \multicolumn{2}{|l|}{ Patient perspectives } & \multicolumn{2}{|c|}{ Community perspectives } \\
\hline & $\begin{array}{l}\text { Adjusted } \beta \text {-coef } \\
(95 \% \mathrm{CI})\end{array}$ & $p$ value & $\begin{array}{l}\text { Adjusted } \beta \text {-coef } \\
(95 \% \mathrm{CI})\end{array}$ & $p$ value \\
\hline \multicolumn{5}{|c|}{ Policy on border closure due to COVID-19 } \\
\hline Before & Reference & & Reference & \\
\hline During & $-3.8(-7.1,-0.5)$ & 0.023 & $-1.6(-5.2,2.0)$ & 0.389 \\
\hline \multicolumn{5}{|l|}{$\mathrm{HI}$ at TB diagnosis } \\
\hline No & Reference & & Reference & \\
\hline Yes & $-0.2(-3.4,3.0)$ & 0.907 & $1.1(-2.5,4.6)$ & 0.545 \\
\hline \multicolumn{5}{|l|}{ Documentation status } \\
\hline No & Reference & & Reference & \\
\hline Yes & $-5.4(-8.5,-2.2)$ & 0.001 & $-4.7(-8.2,-1.2)$ & 0.008 \\
\hline \multicolumn{5}{|l|}{ Ethnicity } \\
\hline Burmese & Reference & & Reference & \\
\hline Karen & $-3.4(-6.1,-0.6)$ & 0.017 & $-4.3(-7.3,-1.3)$ & 0.006 \\
\hline Others & $-0.7(-3.8,2.3)$ & 0.630 & $-0.4(-3.7,2.9)$ & 0.811 \\
\hline \multicolumn{5}{|l|}{ Education level } \\
\hline Primary school and below & Reference & & Reference & \\
\hline Above primary school & $-2.3(-4.6,-0.1)$ & 0.042 & $-1.2(-3.7,1.3)$ & 0.336 \\
\hline \multicolumn{5}{|l|}{ Had job at TB diagnosis } \\
\hline Yes & Reference & & Reference & \\
\hline No & $-0.3(-3.5,2.9)$ & 0.851 & $1.3(-2.2,4.8)$ & 0.466 \\
\hline \multicolumn{5}{|l|}{ Thai language } \\
\hline No or a few words & Reference & & Reference & \\
\hline Fluent & $1.8(-1.4,4.9)$ & 0.267 & $-0.6(-4.0,2.9)$ & 0.750 \\
\hline \multicolumn{5}{|l|}{ Type of household } \\
\hline Living alone & Reference & & Reference & \\
\hline Living with family & $-3.7(-6.6,-0.7)$ & 0.014 & $-3.3(-6.5,-0.1)$ & 0.044 \\
\hline Living with other people & $-4.5(-9.0,0.0)$ & 0.049 & $-2.9(-7.9,2.0)$ & 0.243 \\
\hline \multicolumn{5}{|l|}{ Income level (Baht) } \\
\hline$<5000$ & Reference & & Reference & \\
\hline$\geq 5000$ & $-0.6(-3.1,1.8)$ & 0.607 & $-1.0(-3.7,1.7)$ & 0.471 \\
\hline \multicolumn{5}{|l|}{ Perception of severity of TB } \\
\hline High & Reference & & Reference & \\
\hline Low & $-4.6(-6.8,-2.5)$ & $<0.001$ & $-3.9(-6.3,-1.4)$ & 0.002 \\
\hline \multicolumn{5}{|l|}{ Interaction terms } \\
\hline Policy (During)*HI (Yes) & $-6.3(-11.2,-1.3)$ & 0.014 & $-5.9(-11.4,-0.5)$ & 0.033 \\
\hline Policy (During)*Documented (Yes) & $6.3(1.7,11.0)$ & 0.008 & $6.2(1.1,11.3)$ & 0.018 \\
\hline
\end{tabular}

$\beta$-coef beta-coefficient; $C I$ confidence interval; $T B$ tuberculosis; $H I$ health insurance status of having health insurance possibly helping migrants reduce the feeling and experiences of being ignored, disrespected, or rushed and longer waiting times while accessing the healthcare facilities [27, 28]. Likewise, the documented migrants with TB had lower stigma compared with undocumented migrants before the policy on border closure due to COVID-19. In contrast, there were no significant differences of TB-related stigma scores during the policy which was due to reduced stigma of patient perspective in the undocumented and increased stigma of community perspective in the documented. There was no previous study to compare this finding. We assumed that this may be related to the opportunity of staying in Thailand during the policy on border closure due to COVID-19 for migrants regardless of documentation status. However, migrants might still perceive community stigma due to the COVID-19 infections among migrants during early waves of COVID-19 pandemic in the border area of Thailand.

No significant changes in social support by health insurance and documentation status were found before and during Thailand's policy on border closure due to COVID-19. There has been no direct literature comparing the social 
Table 3 Scores of tuberculosisrelated stigma by health insurance and documentation status stratified by the period of Thailand's policy on border closure due to COVID-19

\begin{tabular}{|c|c|c|c|c|}
\hline \multirow[b]{2}{*}{ Variable } & \multicolumn{4}{|c|}{ Thailand's policy on border closure due to COVID-19 } \\
\hline & $\begin{array}{l}\text { Before, } n=117 \\
\text { Mean }(S D)\end{array}$ & $p$ value & $\begin{array}{l}\text { During, } n=112 \\
\text { Mean }(S D)\end{array}$ & $p$ value \\
\hline Patient perspectives & $27.5(8.7)$ & & $26.4(9.1)$ & 0.375 \\
\hline Health insurance status & & 0.054 & & $<0.001$ \\
\hline No & 28.7 (8.8) & & $28.3(8.5)$ & \\
\hline Yes & $25.6(8.1)$ & & $20.9(8.9)$ & \\
\hline Documentation status & & 0.003 & & 0.493 \\
\hline No & $30.2(8.2)$ & & $27.0(8.1)$ & \\
\hline Yes & $25.5(8.5)$ & & $25.9(10)$ & \\
\hline Community perspectives & $30.0(8.9)$ & & $30.8(9.6)$ & 0.488 \\
\hline Health insurance status & & 0.395 & & 0.012 \\
\hline No & $30.5(9.0)$ & & $32.2(9.3)$ & \\
\hline Yes & $29.1(8.9)$ & & $26.8(9.5)$ & \\
\hline Documentation status & & 0.012 & & 0.979 \\
\hline No & $32.3(8.2)$ & & $30.8(9.8)$ & \\
\hline Yes & $28.2(9.1)$ & & $30.9(9.5)$ & \\
\hline
\end{tabular}

SD, standard deviation support among migrants with TB in terms of health insurance and documentation. This may be explained by several means to communicate through available media with family in the country of origin or living with other migrant peers in the host country $[21,25]$ and social problems such as acculturation, language barriers, and social functions in the host countries [29] that may be minimized by policy of physical distancing during COVID-19 pandemic, similar to the control measures of TB [30]; therefore, we could not find the effect of health insurance and documentation status.

In our study, Karen migrants with TB were less likely to have stigma of patient and community perspectives than Burmese migrants. This can be explained by variations of cultural and geographical response to TB-related stigma [31]. In addition, low level of perceived severity of TB and high education level were associated with low stigma level. A Cambodian study using the same TB-related stigma tool reported significant association of stigma with perceived severity of TB but not with education level [6]. Myanmar migrants living with family or other people reported lower stigma levels compared to those living alone. This suggested that additive effects of TB illness and related psychological distress may have predisposed their perception of social stigma, which was worsened by their migratory nature [7]. Migrants having above a primary level of education reported higher social support levels, which could have mitigated these effects of TB-related stigma [8].

High TB-related stigma and low social support were found among Myanmar migrants with TB. Evidence of stigma and social support among migrants with TB as a substantial topic are scarce [5]. Studies among Cambodian and Thai TB patients reported lower TB-related stigma of both patient and community perspectives using the same stigma tool, but did not assess the social support [6, 32, 33]. Previous reviews also highlighted TB stigma among migrants and a need for more evidence to quantify TB-related stigma, further interventions and measurement of their effectiveness $[5,34]$.

To our knowledge, this is the first study in Thailand that examined the effect of health insurance and documentation status on stigma and social support among Myanmar migrants before and during Thailand's policy on border closure due to COVID-19. While COVID-19 pandemic and subsequent policy of control significantly change the context of the study, the study used previously validated tools to measure stigma and social support as well as the objective measures of available health insurance and documentation status that are specific to the context of migrants. This presented a unique and valid opportunity to compare the stigma and social support levels between two migrant groups before and during Thailand's policy on border closure adjusted with migrant's health insurance and documentation status.

There were some limitations in this study. First, we applied before-after design reflecting the assessment of stigma and social support on TB, not the COVID-19 situation. Second, the study did not include some variables which may also impact on stigma and social support of migrants such as social trust or social support networks [35, 36]. Third, stigma and social support scores were self-reported on recent accounts of migrant's previous perception and experience. Hence, recall bias might be present but minimal. Fourth, the study focused on Myanmar migrants with TB residing in this border area and its generalizability was limited by cultural and geographical variations [24]. Finally, 
Table 4 Social support scores in different characteristics of participants

\begin{tabular}{|c|c|c|c|c|}
\hline \multirow[t]{2}{*}{ Variable } & \multicolumn{2}{|c|}{ Socio-emotional } & \multicolumn{2}{|l|}{ Instrumental } \\
\hline & Mean $(S D)$ & $p$ value & Mean $(S D)$ & $p$ value \\
\hline & $13.7(7.8)$ & & $13.2(8.1)$ & \\
\hline Age categories (years) & & 0.077 & & 0.045 \\
\hline $18-30$ & $3.5(7.9)$ & & $13.1(7.7)$ & \\
\hline $31-40$ & $15.4(8.5)$ & & $15.0(8.7)$ & \\
\hline $41-80$ & $12.6(7.0)$ & & $11.8(7.6)$ & \\
\hline Sex & & 0.195 & & 0.611 \\
\hline Male & $14.6(7.7)$ & & $13.5(7.9)$ & \\
\hline Female & $13.2(7.9)$ & & $12.9(8.2)$ & \\
\hline Ethnicity & & 0.623 & & 0.501 \\
\hline Burmese & $13.9(7.7)$ & & $13.6(8.0)$ & \\
\hline Karen & $12.8(7.8)$ & & $12.1(8.1)$ & \\
\hline Others & $14.2(8.3)$ & & $12.8(8.2)$ & \\
\hline Education level & & 0.008 & & 0.008 \\
\hline Primary school and below & $12.5(7.4)$ & & $11.9(7.7)$ & \\
\hline Above primary school & $15.3(8.1)$ & & $14.8(8.3)$ & \\
\hline Had job at TB diagnosis & & 0.188 & & 0.012 \\
\hline Yes & $12.2(7.7)$ & & $10.5(6.7)$ & \\
\hline No & $14.0(7.8)$ & & $13.7(8.2)$ & \\
\hline Residing in Mae Sot & & 0.144 & & 0.661 \\
\hline No & $12.4(8.1)$ & & $12.7(8.8)$ & \\
\hline Yes & $14.2(7.7)$ & & $13.3(7.8)$ & \\
\hline Type of household & & 0.406 & & 0.386 \\
\hline Living alone & $12.3(7.7)$ & & $12.6(8.3)$ & \\
\hline Living with family & $14.1(7.9)$ & & $13.5(8.2)$ & \\
\hline Living with other people & $13.8(6.9)$ & & $11.1(6.6)$ & \\
\hline Health insurance status & & 0.024 & & 0.042 \\
\hline No & $13.0(7.9)$ & & $12.4(8.1)$ & \\
\hline Yes & $15.4(7.4)$ & & $14.7(7.7)$ & \\
\hline Documentation status & & 0.453 & & 0.058 \\
\hline No & $13.3(7.6)$ & & $12.0(8.0)$ & \\
\hline Yes & $14.1(7.9)$ & & $14.1(8.1)$ & \\
\hline Thai language & & 0.571 & & 0.506 \\
\hline No or a few words & $13.8(7.9)$ & & $13.3(8.2)$ & \\
\hline Fluent & $13.1(7.1)$ & & $12.4(6.9)$ & \\
\hline Income level (Baht) & & 0.174 & & 0.074 \\
\hline$<5000$ & $12.5(7.6)$ & & $11.8(8.5)$ & \\
\hline$\geq 5000$ & $14.6(7.9)$ & & $14.3(7.8)$ & \\
\hline None & $14.1(7.5)$ & & $12.3(6.6)$ & \\
\hline TB knowledge & & 0.277 & & 0.021 \\
\hline High & $14.2(8.0)$ & & $14.2(8.7)$ & \\
\hline Low & $13.1(7.5)$ & & $11.8(7.0)$ & \\
\hline Perception of severity of TB & & 0.318 & & 0.754 \\
\hline High & $14.2(7.9)$ & & $13.3(8.3)$ & \\
\hline Low & $13.1(7.6)$ & & $13.0(7.8)$ & \\
\hline Patient satisfaction with health services & & 0.227 & & 0.174 \\
\hline High & $14.0(7.6)$ & & $13.8(8.4)$ & \\
\hline Low & $13.7(8.1)$ & & $12.7(7.6)$ & \\
\hline Bacteriologically confirmed TB & & 0.810 & & 0.303 \\
\hline Yes & $13.6(8.0)$ & & $12.6(7.8)$ & \\
\hline No* & $13.9(7.6)$ & & $13.7(8.4)$ & \\
\hline
\end{tabular}

$S D$ standard deviation; $T B$ tuberculosis; $H I$ health insurance

*Included smear negative/clinician diagnosed TB/extrapulmonary TB 
Table 5 Final linear regression model of factors associated with social support scores

\begin{tabular}{|c|c|c|c|c|}
\hline \multirow[t]{2}{*}{ Variable } & \multicolumn{2}{|l|}{ Socio-emotional } & \multicolumn{2}{|l|}{ Instrumental } \\
\hline & $\begin{array}{l}\text { Adjusted } \beta \text {-coef } \\
(95 \% \mathrm{CI})\end{array}$ & $p$ value & $\begin{array}{l}\text { Adjusted } \beta \text {-coef } \\
(95 \% \mathrm{CI})\end{array}$ & $p$ value \\
\hline \multicolumn{5}{|c|}{ Policy on border closure due to COVID-19 } \\
\hline Before & Reference & & Reference & \\
\hline During & $-1.1(-4.4,2.1)$ & 0.489 & $-0.8(-4.1,2.5)$ & 0.635 \\
\hline \multicolumn{5}{|l|}{$\mathrm{HI}$ at $\mathrm{TB}$ diagnosis } \\
\hline No & Reference & & Reference & \\
\hline Yes & $0.7(-2.4,3.9)$ & 0.652 & $1.2(-2.1,4.4)$ & 0.477 \\
\hline \multicolumn{5}{|l|}{ Documentation status } \\
\hline No & Reference & & Reference & \\
\hline Yes & $0.4(-2.7,3.4)$ & 0.818 & $1.0(-2.2,4.1)$ & 0.550 \\
\hline \multicolumn{5}{|l|}{ Ethnicity } \\
\hline Burmese & Reference & & Reference & \\
\hline Karen & $-0.6(-3.3,2.0)$ & 0.634 & $-0.3(-3.1,2.4)$ & 0.815 \\
\hline Others & $0.1(-2.8,3.1)$ & 0.934 & $-0.9(-4.0,2.1)$ & 0.546 \\
\hline \multicolumn{5}{|l|}{ Education level } \\
\hline Primary school and below & Reference & & Reference & \\
\hline Above primary school & $2.3(0.1,4.5)$ & 0.040 & $2.5(0.2,4.7)$ & 0.031 \\
\hline \multicolumn{5}{|l|}{ Had job at TB diagnosis } \\
\hline Yes & Reference & & Reference & \\
\hline No & $-1.5(-4.6,1.6)$ & 0.332 & $-3.0(-6.1,0.2)$ & 0.068 \\
\hline \multicolumn{5}{|l|}{ Thai language } \\
\hline No or a few words & Reference & & Reference & \\
\hline Fluent & $-0.9(-3.9,2.2)$ & 0.577 & $-0.8(-3.9,2.4)$ & 0.628 \\
\hline \multicolumn{5}{|l|}{ Type of household } \\
\hline Living alone & Reference & & Reference & \\
\hline Living with family & $1.9(-0.9,4.8)$ & 0.188 & $1.0(-1.9,3.9)$ & 0.506 \\
\hline Living with other people & $0.7(-3.8,5.1)$ & 0.768 & $-3.0(-7.5,1.6)$ & 0.197 \\
\hline \multicolumn{5}{|l|}{ Income level (Baht) } \\
\hline$<5000$ & Reference & & Reference & \\
\hline$\geq 5000$ & $0.9(-1.5,3.4)$ & 0.442 & $1.0(-1.4,3.5)$ & 0.407 \\
\hline \multicolumn{5}{|l|}{ Perception of severity of TB } \\
\hline High & Reference & & Reference & \\
\hline Low & $-1.7(-3.9,0.4)$ & 0.109 & $-1.1(-3.3,1.1)$ & 0.324 \\
\hline \multicolumn{5}{|l|}{ Interaction terms } \\
\hline Policy (During)*HI (Yes) & $2.1(-2.8,7.0)$ & 0.400 & $0.0(-5.0,5.0)$ & 0.994 \\
\hline Policy (During)*Documented (Yes) & $-1.0(-5.6,3.6)$ & 0.665 & $1.2(-3.5,5.8)$ & 0.629 \\
\hline
\end{tabular}

$\beta$-coef beta-coefficient; $C I$ confidence interval; $T B$ tuberculosis; $H I$ health insurance approximately one-third of migrants in our study had health insurance, even though insurance packages are available for migrants in Thailand. The explanation of this low rate may be related to unaffordability of insurance costs, not perceiving health needs for insurance purchasing, not having proper working documents, or lack of knowledge about health insurance that was revealed from our qualitative interview (unpublished).

The findings of our study outstretched the effects of the policy on stigma and social support experienced among Myanmar migrant population during COVID-19 pandemic. The efforts to promote health insurance and documentation among Myanmar migrants including offering documentation process with minimal affordable fees and extension of their legal stay in Thailand by the stakeholders and policymakers should be strengthened. In addition, COVID-19 measures that help reduce the intimidation of the undocumented should be carefully designed and implemented, so that they will be more than willing to come forth to the healthcare center if they show symptoms of either COVID-19 or TB. 
Table 6 Scores of social support by health insurance and documentation status stratified by Thailand's policy on border closure due to COVID-19

\begin{tabular}{|c|c|c|c|c|}
\hline \multirow[b]{2}{*}{ Variable } & \multicolumn{4}{|c|}{ Thailand's policy on border closure due to COVID-19 } \\
\hline & $\begin{array}{l}\text { Before, } n=117 \\
\text { Mean }(S D)\end{array}$ & Variable & $\begin{array}{l}\text { During, } n=112 \\
\text { Mean }(S D)\end{array}$ & $p$ value \\
\hline Socio-emotional & $14.5(7.7)$ & & $12.9(7.9)$ & 0.111 \\
\hline Health insurance status & & 0.280 & & 0.082 \\
\hline No & $14.0(8.2)$ & & $12.1(7.6)$ & \\
\hline Yes & $15.5(6.7)$ & & $15.3(8.4)$ & \\
\hline Documentation status & & 0.440 & & 0.861 \\
\hline No & $13.9(7.8)$ & & $12.8(7.6)$ & \\
\hline Yes & $15.0(7.6)$ & & $13.0(8.2)$ & \\
\hline Instrumental & $13.6(8.1)$ & & $12.7(8.0)$ & 0.367 \\
\hline Health insurance status & & 0.166 & & 0.204 \\
\hline No & $12.8(8.5)$ & & $12.1(7.8)$ & \\
\hline Yes & $14.9(7.2)$ & & $14.4(8.6)$ & \\
\hline Documentation status & & 0.202 & & 0.186 \\
\hline No & $12.5(8.5)$ & & $11.6(7.5)$ & \\
\hline Yes & $14.5(7.8)$ & & $13.6(8.4)$ & \\
\hline
\end{tabular}

$S D$ standard deviation

\section{Conclusion}

The effect modification of Thailand's policy on border closure due to COVID-19 on the relationship between health insurance, documentation status, and TB-related stigma among Myanmar migrants with TB in a border area of Myanmar and Thailand was found. Future studies on the health insurance and documentation status among migrants extending to other regions in Asia using mixed methods to improve TB-related stigma and social support are warranted.

Supplementary Information The online version contains supplementary material available at https://doi.org/10.1007/s40615-021-01185-3.

Acknowledgements The study was part of the $\mathrm{PhD}$ degree fulfillment of the first author at Prince of Songkla University supported under the scholarship of Thailand's Education Hub for Southern Region of ASEAN countries. We would like to thank all patients who participated in our study and the health personnel from the local clinics who helped with data collection.

Author Contribution Conceptualization and methodology: MMO, TL, NB, HKKA, PP. Data collection: MMO, TL, NB, HKKA. Data analysis: MMO, TL. Writing — original draft preparation, MMO, TL. Writing-review and editing, MMO, TL, NB, HKKA, PP. All authors have read and agreed to the published version of the manuscript.

Funding The research was also supported by the TB/MDR-TB research training program at the Epidemiology Unit, Faculty of Medicine, Prince of Songkla University under the support of the Fogarty International Center, National Institutes of Health (Grant number: D43TW009522), and the Health System Research Institute, Bangkok, Thailand (Grant number: 62-082). The funders had no role in study design, data collection and analysis, decision to publish or preparation of the manuscript.
Data Availability The datasets used and/or analyzed during the current study are available from the corresponding author on reasonable request.

Code Availability The custom codes used during the current study are available from the corresponding author on reasonable request.

\section{Declarations}

Ethics Approval and Consent to Participate Ethical clearance for the study was obtained from the Institutional Ethics Committee of the Faculty of Medicine, Prince of Songkla University (REC.62-155-18-1) and from the Institutional Review Board at Mae Sot General Hospital (MSHP 009/2562). Each patient was informed of the study's purpose before the interview and informed consent was verbally obtained due to the sensitive nature and confidentiality of immigration status in this border area. They were informed of their full right to participate or decline to do so in the study with no prejudice to their treatment. The anonymity and confidentiality of all patients were stringently maintained throughout the study.

Consent for Publication Not applicable.

Competing Interests The authors declare no competing interests.

\section{References}

1. World Health Organization (WHO). Global tuberculosis report 2019. WHO: Geneva; 2019.

2. Chuengsatiansup K, Limsawart W. Tuberculosis in the borderlands: migrants, microbes and more-than-human borders. Palgrave Commun. 2019;5:31.

3. International Organization for Migration. World Migration Report 2020 [Internet]. IOM:Geneva; 2020. Available from: https://publi cations.iom.int/system/files/pdf/wmr_2020.pdf. 
4. Department of Disease Control. Thailand operational plan to end tuberculosis 2017-2021 [Internet]. Ministry of Public Health:Nonthaburi; 2017. Available from: https://www.tbtha iland.org/download/Manual/Thailand Operational Plan To End TB_2017_2021.pdf.

5. Craig GM, Daftary A, Engel N, O'Driscoll S, Ioannaki A. Tuberculosis stigma as a social determinant of health: a systematic mapping review of research in low incidence countries. Int J Infect Dis. 2017;56:90-100.

6. Teo AKJ, Tan RKJ, Smyth C, Soltan V, Eng S, Ork C, et al. Characterizing and measuring tuberculosis stigma in the community: a mixed-methods study in Cambodia. Open forum Infect Dis. 2020;7:ofaa422.

7. Makowski AC, von dem Knesebeck O. Depression stigma and migration - results of a survey from Germany. BMC Psychiatry [Internet]. 2017;17:381. Available from: https://doi.org/10. 1186/s12888-017-1549-y

8. Li J, Mo PKH, Wu AMS, Lau JTF. Roles of self-stigma, social support, and positive and negative affects as determinants of depressive symptoms among HIV infected men who have sex with men in China. AIDS Behav [Internet]. 2017;21:261-73. Available from: https://pubmed.ncbi.nlm.nih.gov/26896120

9. Tangcharoensathien V, Thwin AA, Patcharanarumol W. Implementing health insurance for migrants. Thailand Bull World Health Organ. 2017;95:146-51.

10. Wongkongdech R, Srisaenpang S, Tungsawat S. Pulmonary TB among Myanmar migrants in Samut Sakhon Province, Thailand: a problem or not for the TB control program? Southeast Asian J Trop Med Public Health. 2015;46:296-305.

11. Datiko DG, Jerene D, Suarez P. Stigma matters in ending tuberculosis: nationwide survey of stigma in Ethiopia. BMC Public Health [Internet]. 2020;20:190. Available from: https://doi.org/ 10.1186/s12889-019-7915-6

12. Churcher S. Stigma related to HIV and AIDS as a barrier to accessing healthcare in Thailand: a review of recent literature. WHO South East Asia J Public Health. 2013;2:12-22.

13. Tschirhart N, Sein T, Nosten F, Foster AM. Migrant and refugee patient perspectives on travel and tuberculosis along the Thailand-Myanmar border: a qualitative study. PLoS One [Internet]. 2016;11:1-12. Available from: https://doi.org/10.1371/journal. pone. 0160222

14. Tschirhart N, Thi SS, Swe LL, Nosten F, Foster AM. Treating the invisible: gaps and opportunities for enhanced TB control along the Thailand-Myanmar border. BMC Health Serv Res. 2017; 17:29.

15. Gronholm PC, Nosé M, van Brakel WH, Eaton J, Ebenso B, Fiekert K, et al. Reducing stigma and discrimination associated with COVID-19: early stage pandemic rapid review and practical recommendations. Epidemiol Psychiatr Sci [Internet]. 2021;30:e15. Available from: https://pubmed.ncbi.nlm.nih.gov/ 33504412

16. Hogan AB, Jewell BL, Sherrard-Smith E, Vesga JF, Watson OJ, Whittaker C, et al. Potential impact of the COVID-19 pandemic on HIV, tuberculosis, and malaria in low-income and middleincome countries: a modelling study. Lancet Glob Health. 2020;8:e1132-41.

17. World Health Organization. WHO Director-General's opening remarks at the media briefing on COVID-19 - 11 March 2020. WHO: Geneva; 2020.

18. Chu DK, Akl EA, Duda S, Solo K, Yaacoub S, Schünemann $\mathrm{HJ}$, et al. Physical distancing, face masks, and eye protection to prevent person-to-person transmission of SARS-CoV-2 and COVID-19: a systematic review and meta-analysis. Lancet [Internet]. 2020;395:1973-87. Available from: https://doi.org/ $10.1016 /$ S0140-6736(20)31142-9
19. Engblom A, Lephilibert N, Barua N. COVID-19: Impact on migrant workers and country response in Thailand. International Labour Organization Country Office for Thailand, Cambodia and Lao PDR: International Labour Organization; 2020.

20. International Organization for Migration. Rapid assessment: COVID-19 related vulnerabilities and perceptions in Mae Sot district, Tak province, Thailand. IOM Thailand: Bangkok; 2020.

21. Rhodes SD, Daniel J, Song E-Y, Alonzo J, Downs M, Reboussin BA. Social support among immigrant Latino men: a validation study. Am J Health Behav. 2013;37:620-8.

22. World Health Organization (WHO). Advocacy, communication and social mobilization for TB control: a guide to developing knowledge, attitude, and practice surveys. WHO: Geneva; 2008.

23. Thayaparan AJ, Mahdi E. The patient satisfaction questionnaire short form (PSQ-18) as an adaptable, reliable, and validated tool for use in various settings. Med Educ Online [Internet]. 2013;18:21747. Available from: https://doi.org/10.3402/meo. v18i0.21747

24. Van Rie A, Sengupta S, Pungrassami P, Balthip Q, Choonuan S, Kasetjaroen $\mathrm{Y}$, et al. Measuring stigma associated with tuberculosis and HIV/AIDS in southern Thailand: exploratory and confirmatory factor analyses of two new scales. Trop Med Int Health. 2008;13:21-30.

25. Ong ASJ, Ward C. The construction and validation of a social support measure for Sojourners: the Index of Sojourner Social Support (ISSS) Scale. J Cross Cult Psychol [Internet]. 2005;36:637-61. Available from: https://doi.org/10.1177/00220 22105280508

26. Driessche K Vanden, Mahlobo PZ, Venter R, Caldwell J, Jennings K, Diacon AH, et al. Face masks in the post-COVID-19 era: a silver lining for the damaged tuberculosis public health response? Lancet Respir Med [Internet]. 2021;9:340-2. Available from: https://doi.org/10.1016/S2213-2600(21)00020-5.

27. Horton S. The double burden on safety net providers: placing health disparities in the context of the privatization of health care in the US. Soc Sci Med. 2006;63:2702-14.

28. Martinez-Hume AC, Baker AM, Bell HS, Montemayor I, Elwell K, Hunt LM. "They treat you a different way:" public insurance, stigma, and the challenge to quality health care. Cult Med Psychiatry. 2017;41:161-80.

29. Dail PW. Immigration and migration in America: social impact and social response. Int Migr [Internet]. 1988;26:441-52. Available from: https://doi.org/10.1111/j.1468-2435.1988.tb00663.x

30. Williams CYK, Townson AT, Kapur M, Ferreira AF, Nunn R, Galante $\mathbf{J}$, et al. Interventions to reduce social isolation and loneliness during COVID-19 physical distancing measures: a rapid systematic review. PLoS One. 2021;16:e0247139.

31. Chang S-H, Cataldo JK. A systematic review of global cultural variations in knowledge, attitudes and health responses to tuberculosis stigma. Int J Tuberc lung Dis. 2014;18:168-73, i-iv.

32. Kipp AM, Pungrassami P, Stewart PW, Chongsuvivatwong V, Strauss RP, Van Rie A. Study of tuberculosis and AIDS stigma as barriers to tuberculosis treatment adherence using validated stigma scales. Int J Tuberc lung Dis. 2011;15(1540-5):i.

33. Kipp AM, Audet CM, Earnshaw VA, Owens J, McGowan CC, Wallston KA. Re-validation of the Van Rie HIV/AIDS-related stigma scale for use with people living with HIV in the United States. PLoS One. 2015;10:e0118836.

34. Sommerland N, Wouters E, Mitchell EMH, Ngicho M, Redwood $\mathrm{L}$, Masquillier C, et al. Evidence-based interventions to reduce tuberculosis stigma: a systematic review. Int J Tuberc lung Dis. 2017;21:81-6.

35. Zeng C, Li X, Du H, Lin D. Experiences of stigma and health service utilization among young rural-to-urban migrants in China: the mediation role of social capital. Vulnerable Child Youth Stud. 2020;15:97-109. 
36. Kirwan DE, Nicholson BD, Baral SC, Newell JN. The social reality of migrant men with tuberculosis in Kathmandu: implications for DOT in practice. Trop Med Int Health [Internet]. 2009;14:1442-7. Available from: https://doi.org/10.1111/j. 1365-3156.2009.02405.x

Publisher's Note Springer Nature remains neutral with regard to jurisdictional claims in published maps and institutional affiliations. 